\title{
Mode I Fracture Behaviors between Cement Concrete and Asphalt Concrete Layer
}

\author{
Zhongping Tang $\mathbb{D}^{1}{ }^{1}$ Fanglin Huang $\mathbb{D}^{1},{ }^{1}$ and Hua Peng ${ }^{2}$ \\ ${ }^{1}$ School of Civil Engineering, Central South University, 22 South Shaoshan Rd., Changsha, Hunan 410075, China \\ ${ }^{2}$ Zhejiang Xinjie Construction Co., Ltd., Ningbo, Zhejiang, China \\ Correspondence should be addressed to Fanglin Huang; huangfanglin@csu.edu.cn
}

Received 12 November 2020; Revised 20 December 2020; Accepted 27 January 2021; Published 9 February 2021

Academic Editor: Xun Xi

Copyright (C) 2021 Zhongping Tang et al. This is an open access article distributed under the Creative Commons Attribution License, which permits unrestricted use, distribution, and reproduction in any medium, provided the original work is properly cited.

\begin{abstract}
Asphalt overlay or concrete overlay on existing pavements is a common strategy for pavement maintenance. Interlayer bonding performance between asphalt and concrete layers is a critical concern in achieving optimal long-term structural performance due to the possible cracking along the interface. In this study, bonding behaviors of asphalt concrete interface were characterized by employing mode I fracture tests conducted at -10 and $25^{\circ} \mathrm{C}$, respectively. Two typical interface conditions were manually prepared. A tack coat material was applied on the interface with four distinct rates: $0.1,0.2,0.3$, and $0.4 \mathrm{~L} / \mathrm{m}^{2}$. Parameters including fracture strength, stress intensity factor $\left(K_{\mathrm{IC}}\right)$, facture energy $\left(G_{\mathrm{F}}\right)$, and energy release rate (J integral) were selected to evaluate the fracture performance. Results showed that optimum tack coat rates were 0.1 and $0.3 \mathrm{~L} / \mathrm{m}^{2}$ for specimens with unmilled and milled surfaces. At the optimum tack coat rates, $K_{\mathrm{IC}}$ and $G_{\mathrm{F}}$ increased with the increase of interface roughness at $-10^{\circ} \mathrm{C}$, while, at $25^{\circ} \mathrm{C}, J$ integral of specimens with unmilled interface was larger than that of specimens with milled interface at the optimum tack coat rates. Analysis of variance (ANOVA) was conducted to evaluate the significance of the factors on the fracture loads and found that surface roughness is significant at $-10^{\circ} \mathrm{C}$ and becomes nonsignificant at $25^{\circ} \mathrm{C}$. Temperature and tack coat rate were significant factors considering a given interface.
\end{abstract}

\section{Introduction}

Under the repeated climatic effects and traffic loading, the service process of pavements is accompanied by the occurrence and expansion of distresses, resulting in the performance degradation. Rehabilitation is a critical maintenance strategy which could repair portions of an existing pavement to reset the deterioration process. Portland cement concrete overlay or asphalt overlay on existing pavements is a common implementation approach in rehabilitation [1-3] (Figure 1). Among the overlay structures in Figure 1, asphalt overlay on existing concrete pavement and concrete overlay on existing asphalt pavement are gaining momentum due to the different materials combination of the topping and underlying layers. Asphalt overlay on existing concrete pavement is proved to be an effective coping strategy to resist reflective cracking [4]. Overlay paving could address various purposes from the structural to functional benefits considering the different design procedures $[5,6]$. However, lots of failures initiate at the interfacial edge corner due to the existence of the stress singularities under the effects of various factors, including loading, water, temperature, etc. [7]. On the other hand, the coating material between overlay and the existing substrate brings the uncertainty of bonding evolution and the complexity of bonding evaluation. In addition, environmental factors, such as temperature and moisture, could play different roles on asphalt and concrete layers, leading to the uncoordinated stress and strain behaviors, which induce significant shear stress along the interface. The performance and reliability of coatings rely on the integrity of the "Overlay-Coating-Existing substrate" system. Therefore, the bonding performance between cement concrete and asphalt concrete is a critical concern to ensure the durability of overlay paving.

The mechanisms of coating adhesion include the following aspects: (1) interfacial adhesion on a thin interface; (2) 

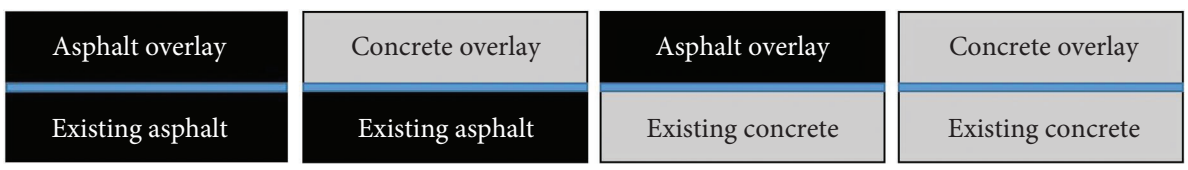

FIgURE 1: Bonded overlays.

interdiffusion bonding between the coating and the substrate on a relatively thick interfacial region; (3) interlocking effect in which the coating/substrate interface is relatively rough [8-10]. In the bonding between asphalt layers, tack coat materials are generally bituminous emulsions [11], in which cationic emulsions are the most commonly used. The bonding strength provided by a coating material is a function of various factors, including coating materials, surface condition, temperature, type of asphalt mixtures, etc. Considering the tack coat, it has been reported that the tack coat type, application rate, and their viscoelastic behaviors all significantly affected the bonding behaviors [6, 11-15]. Zhang [15] made a review about the application of tack coat in asphalt pavement in US. The optimal tack coat application rates varied from 0 to $0.97 \mathrm{~L} / \mathrm{m}^{2}$ for different types of tack coats at different temperatures. Wang et al. [11] summarized the results from 8 papers and found that the optimum application rates were in the range of 0.1 to $0.7 \mathrm{~L} / \mathrm{m}^{2}$. In cement concrete layer bonding, cement mortar, epoxy agent and SBR-latex, etc. [16-18] are generally used to create an adequate layer bonding. In these candidates, the cement mortar undergoes hydration reaction from a fresh state to a hardened state, so that the bonding agent and concrete layer surface could bond to be a monolith system. The epoxy or latex modified agent could permeate into the voids on the concrete surface and provide a superior bonding. In asphalt overlays, temperature could affect both the behaviors of asphalt layers and tack coat materials, and the bonding behaviors could transition from linear elastic to elastoplastic, resulting in the strength improvement at low temperatures and reduction at high temperatures $[9,19]$. The interface roughness could provide an interlock effect between the topping and underlying layer $[20,21]$. Meanwhile, interface roughness also affects the optimum tack coat application rate. On the other hand, the friction angle and internal cohesion, generated from the Mohr-Coulomb failure criterion, are also influenced by the interface roughness parameters [22, 23]. Ktari et al. [24] found that there existed an intermediate transition zone (ITZ) in the direct tension tests between two asphalt layers, and there was a certain correlation between the surface roughness and ITZ thickness. Texture depth, surface roughness, and fractal dimension, etc. are generally employed to quantificationally present the effects on the bonding performance between layers $[23,25,26]$.

Some studies have been reported about the bonding behaviors between asphalt layer and concrete layer due to the extensive concern on the overlay maintenance strategy. Li et al. [27] found that the asphalt layer was susceptible to fatigue cracking at the locations of the existing transverse joints of the rigid base. Fallah and Khodaii [28] explored the fatigue failure of asphalt overlay reinforced with geogrid and found that the existing layer stiffness was the most significant factor affecting the crack growth rate, followed by overlay stiffness and geogrid strength, and the effect of geogrid type on the crack growth rate was the least, while the coating amount and type of coating had no significant influence on the fatigue life. Bonding could be enhanced by milling the existing pavement to produce a rough interface to lay another type of overlay. Actually, milling process is prerequisite for asphalt overlay on concrete pavements or concrete overlay on asphalt pavements. Jayakesh and Suresha [29] investigated the interface shear bond strength and shear fatigue behavior of whitetopping on existing asphalt pavement. Results showed that groove interface treatment technique inclined at an angle of $45^{\circ}$ could enhance the interface shear strength. Mateos et al. [30] found that the interface stiffness between asphalt and concrete layer showed an obvious temperature and loading-frequency dependency. Another finding was that fatigue failure mainly occurred in the asphalt rather than in the interface.

In the bonding characterization, various test methods are employed nowadays [31], such as tensile tests, shear tests, and torque tests. The most common parameters derived from these tests are the shear strength and the interface shear stiffness $[11,32-34]$. These parameters macroscopically characterize the interlayer bonding performance and reveal the influence of temperature, tack coat, interface roughness, and other factors on the bonding performance. In evaluating the fracture resistance of asphalt concretes, the semi-circular bending (SCB) test has gained particular popularity to assess the characteristics of asphalt mixtures due to its advantages in simplicity, effectiveness, and repeatability [35-37]. The fracture strength, crack mouth opening displacement (CMOD), and energy release rate (J-integral) are generally employed to present the fracture resistance $[35,36,38]$. Although fracture tests were commonly used in properties' characterization of asphalt mixtures and cement concretes $[38,39]$, the application of fracture mechanics in pavement layer cracking is inadequate. Cracking along the interface can be regarded as a fracture process which can be analyzed by using the fracture mechanics. Mirsayar et al. [40] conducted bi-material semi-bend tests to obtain the bonding strength between asphalt layer and concrete layer under mode I and II fracture patterns. Hakimzadeh et al. [41] conducted interface bond test (IBT) and found that the emulsion coating provided a better bond strength than the cationic slow-setting (CSS) coating. On the other hand, fracture energy can be regarded as an appropriate indicator of the quality of the bonding. $\mathrm{Mu}$ et al. [42] conducted wedge splitting tests to quantify mode I fracture along the Portland cement concrete/ hot mix asphalt interface. Results showed that the interface can be modeled as a viscoelastic layer of a defined width. These studies gave some valuable results on the interlaminar behaviors between asphalt and concrete layers. However, the effects of tack coat, interface roughness, and temperature on the fracture behaviors between the layered system still need to be explored to deepen the understanding of interlayer performance. 


\section{Scope of Study}

The present study investigates the influence of temperature, tack coat rate, and surface condition on the bonding between concrete and asphalt layers. For this purpose, the fracture mechanics theory was employed and three-point bending tests (mode I tests) were carried out on notched cubic specimens. Two temperatures $\left(-10\right.$ and $\left.25^{\circ} \mathrm{C}\right)$ and four tack coat application rates $\left(0.1,0.2,0.3\right.$, and $\left.0.4 \mathrm{~L} / \mathrm{m}^{2}\right)$ were adopted in the tests. Fracture strength, stress intensity factor $\left(K_{\mathrm{IC}}\right)$, energy release rate ( $\mathrm{J}$ integral), and fracture energy $\left(G_{\mathrm{F}}\right)$ were selected to evaluate the fracture performance. The findings could contribute to a better understanding of the fracture behaviors between the concrete and asphalt layers to effectively improve the design methods.

\section{Methodology}

3.1. Materials. A type of Chinese standard P.O 42.5 Portland cement was used to prepare the cement concretes. The specific surface area is $320 \mathrm{~m}^{2} / \mathrm{kg}$. The chemical components of the cement can be seen in Table 1. The binder properties in the asphalt concrete are shown in Table 2. Limestone gravel aggregates with the nominal maximum aggregate sizes of 9.5 and $19.5 \mathrm{~mm}$ were selected for asphalt and cement concretes. The aggregate gradations are shown in Figure 2. Concrete mix design is shown in Table 3 . The binder content is $6 \%$ in mass of asphalt concrete. The tack coat in this study is an anionic slow-setting emulsion asphalt, and the residual rate was determined as $45 \%$. Four tack coat residual application rates were used: $0.1,0.2,0.3$, and $0.4 \mathrm{~L} / \mathrm{m}^{2}$. To improve the workability of fresh concretes, a polycarboxylic superplasticizer was selected. It is classified as Type A according to ASTM C494. The recommended dosage is about $1.0 \%$ by weight of the cementitious material.

3.2. Three-Point Bending (TPB) Test Setup. Concrete specimens with a $150 \mathrm{~mm}$ diameter and $75 \mathrm{~mm}$ height were fabricated first. The specimens were cured under a temperature of $20 \pm 2^{\circ} \mathrm{C}$ and a relative humidity of $95 \%$ for 28 days. Then, the coating material was applied on the surface of concrete surfaces using four application rates. After about 2 hours, which is long enough for the tack coat to break the emulsion, the compaction of asphalt mixtures was conducted. Asphalt mixtures were compacted using a Superpave Gyratory Compactor (SGC) with a compaction pressure of $600 \mathrm{kPa}$. Trial tests were conducted to ensure the air void content in asphalt layer was $4 \%$. After the compaction of the asphalt overlay, prism specimens with a dimension of $150 \times 106 \times 53 \mathrm{~mm}$ in height, width, and depth were cut using a water-cooled masonry saw. The sample preparation is shown in Figure 3. To evaluate the effect of interface roughness on the fracture behaviors, surface treatments were conducted on the concrete substrates, and the procedure was the same as [23]. Two different interfaces (milled and unmilled interfaces) considering the surface roughness were prepared. The roughness is arithmetic average value of the deviation of the trace above and below the center plane. The roughness values of the two types specimens were 0.18 and $0.64 \mathrm{~mm}$. The roughness test was conducted following the strategy in [23]. A 3D laser was used to get the three-dimensional coordinates of a surface. Then, the surface roughness values could be calculated using these data.

After the original specimens were prepared, notches with two different lengths $(10$ and $20 \mathrm{~mm})$ were cut. The TPB specimens were loaded monotonically until fracture failure under a constant displacement-controlled rate $0.5 \mathrm{~mm} / \mathrm{min}$ at -10 and $25^{\circ} \mathrm{C}$, respectively. At $-10^{\circ} \mathrm{C}$, the notch length was $10 \mathrm{~mm}$; and at $25^{\circ} \mathrm{C}$, the notch lengths were $10 \mathrm{~mm}$ and $20 \mathrm{~mm}$, which were used for the $J$ integral calculation. A total of $48 \mathrm{TPB}$ specimens were prepared in the laboratory. A schematic of the test setup is shown in Figure 4. The details of the test information can be seen in Table 4 . The length of the supporting span is $120 \mathrm{~mm}$. The specimens are loaded symmetrically. The given test device could ensure the mode I fracture along the interface between asphalt and concrete layers. The load and displacement along the loading point were recorded automatically by a data acquisition system. It should be noted that concrete shrinkage effect exists, which introduces the contraction stress along the interface between asphalt and concrete layer and help accelerate the cracking on the interface. However, the shrinkage effect is not significant after 28 days' curing, and the use of superplasticizer could also mitigate the shrinkage effect $[43,44]$. The shrinkage is not the main concern of this study, and therefore, this factor is not discussed herein.

3.3. Analysis Methodology. At low temperatures, the nonlinear deformation of asphalt concrete is a small region ahead of the crack tip. In this scenario, linear elastic fracture mechanics can be employed to evaluate the fracture performance. Fracture strength $(\sigma)$, stress intensity factor $\left(K_{\mathrm{IC}}\right)$, and fracture energy $\left(G_{\mathrm{F}}\right)$ were measured. Fracture strength is calculated using equation (1) [45]. The stress intensity factor is the magnitude of the stress singularity at the tip of a mathematically sharp crack in a linear elastic material [46]. The magnitude of $K_{\mathrm{IC}}$ depends on specimen geometry, the size and location of the notch, and the magnitude and the distribution of loads on the material. Reference [47] provides the equation for $K_{\mathrm{IC}}$ calculation, shown as

$$
\begin{aligned}
\sigma & =\frac{3 P_{\max } l}{2 t(h-a)^{2}}, \\
K_{\mathrm{IC}} & =\frac{P_{\max } l}{\mathrm{th}^{3 / 2}}\left[2.9\left(\frac{a}{h}\right)^{1 / 2}-4.6\left(\frac{a}{h}\right)^{3 / 2}+21.8\left(\frac{a}{h}\right)^{5 / 2}-37.6\left(\frac{a}{h}\right)^{7 / 2}+38.7\left(\frac{a}{h}\right)^{9 / 2}\right],
\end{aligned}
$$


TABLE 1: Chemical components of cement.

\begin{tabular}{lccccccccc}
\hline Components & $\mathrm{SiO}_{2}$ & $\mathrm{Al}_{2} \mathrm{O}_{3}$ & $\mathrm{Fe}_{2} \mathrm{O}_{3}$ & $\mathrm{CaO}$ & $\mathrm{MgO}$ & $\mathrm{SO}_{3}$ & $\mathrm{Na}_{2} \mathrm{O}$ & $\mathrm{LOI}$ & $\mathrm{Total}$ \\
\hline Amount (\%) & 21.7 & 5.4 & 3.3 & 64.6 & 1.9 & 1.6 & 0.9 & 0.6 & 100 \\
\hline
\end{tabular}

TABle 2: Properties of asphalt binder and tack coat residue.

\begin{tabular}{|c|c|c|c|c|}
\hline Materials & Properties & Units & Requirements & Test results \\
\hline \multirow{5}{*}{ Asphalt } & Penetration $\left(25^{\circ} \mathrm{C}\right)$ & $0.1 \mathrm{~mm}$ & $30-60$ & 54.8 \\
\hline & Ductility $\left(5^{\circ} \mathrm{C}\right)$ & $\mathrm{cm}$ & $\geq 20$ & 30.7 \\
\hline & Soft point & ${ }^{\circ} \mathrm{C}$ & $\geq 60$ & 80.7 \\
\hline & Kinematic viscosity $\left(135^{\circ} \mathrm{C}\right)$ & Pa.s & $\leq 3.0$ & 1.79 \\
\hline & Penetration index & & $\geq 0$ & 0.19 \\
\hline \multirow{2}{*}{ Tack coat } & Penetration $\left(25^{\circ} \mathrm{C}\right)$ & $0.1 \mathrm{~mm}$ & & 79.6 \\
\hline & Ductility $\left(15^{\circ} \mathrm{C}\right)$ & $\mathrm{cm}$ & & 108 \\
\hline
\end{tabular}

Note. The requirements followed the standard (JTG E20-2011 Standard test methods of bitumen and bituminous mixtures for highway engineering).

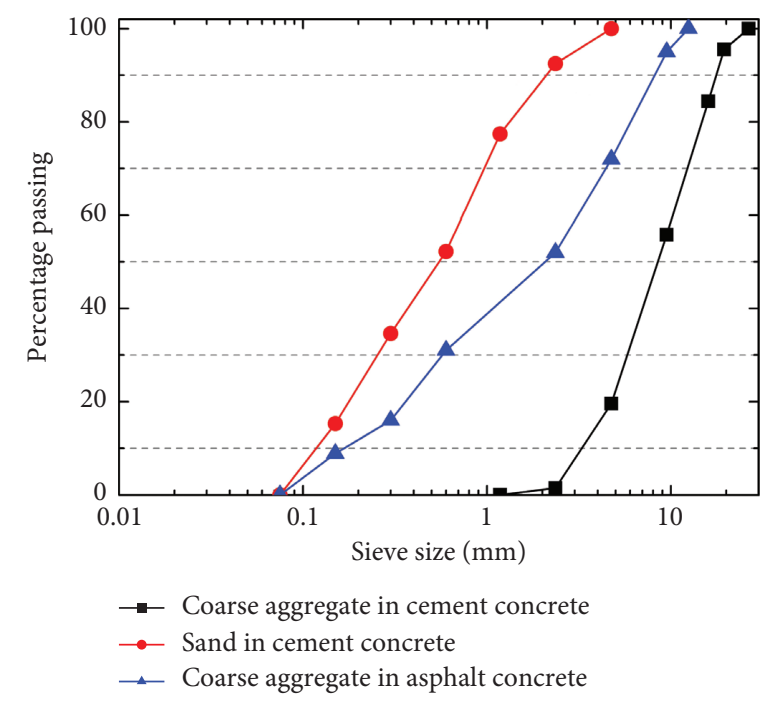

Figure 2: Aggregate gradations.

TABLE 3: Mixture design of cement concrete.

\begin{tabular}{lccccc}
\hline Materials & Cement & Water & Sand & Coarse aggregate & Superplasticizer \\
\hline Mass $\left(\mathrm{kg} / \mathrm{m}^{3}\right)$ & 485 & 155 & 700 & 1145 & 6 \\
\hline
\end{tabular}

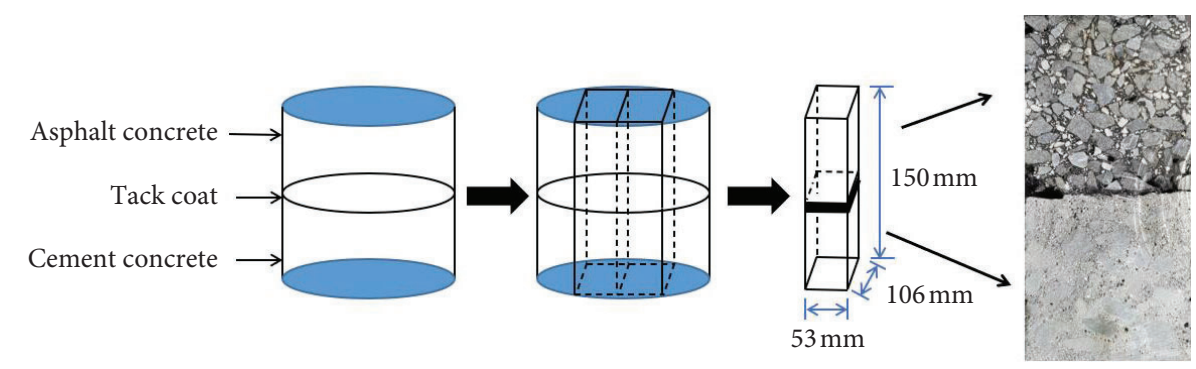

FIGURE 3: Sample preparation. 

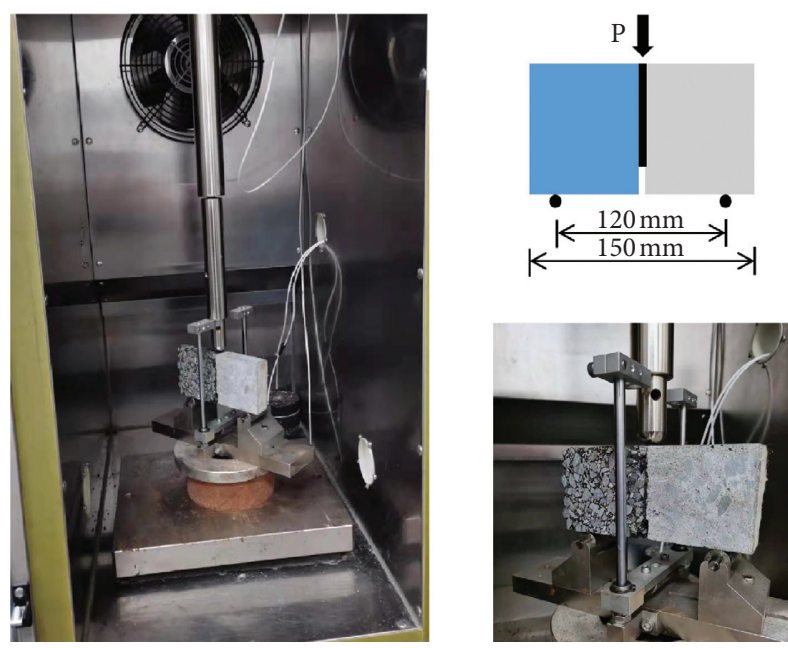

Figure 4: Test setup.

TABLE 4: Testing information.

\begin{tabular}{ccccc}
\hline Temperature $\left({ }^{\circ} \mathrm{C}\right)$ & Tack coat $\left(\mathrm{L} / \mathrm{m}^{2}\right)$ & Interface condition & Notch length $(\mathrm{mm})$ & No. of samples \\
\hline \multirow{3}{*}{-10} & 0.1 & Milled/unmilled & 10 & 4 \\
& 0.2 & Milled/unmilled & 10 & 4 \\
& 0.3 & Milled/unmilled & 10 & 4 \\
\hline & 0.4 & Milled/unmilled & $10 / 20$ & 8 \\
& 0.1 & Milled/unmilled & $10 / 20$ & 8 \\
& 0.2 & Milled/unmilled & $10 / 20$ & 8 \\
& 0.3 & Milled/unmilled & $10 / 20$ & 8 \\
\hline
\end{tabular}

where $P_{\max }$ is the peak load measured in TPB tests when the specimen fractures; $l$ is the span between the two supporting points at which the load is imposed, and here equals $120 \mathrm{~mm}$; $t$ is the width of the specimen, which is $53 \mathrm{~mm}$ in this study; $h$ is the height of the specimen, and here equals $106 \mathrm{~mm}$; and $a$ is the length of the notch, which is $10 \mathrm{~mm}$.

Besides $K_{\mathrm{IC}}$, fracture energy $\left(G_{\mathrm{F}}\right)$ is used to evaluate the fracture toughness [48]. The fracture energy is defined herein as the area covered by the load-displacement curve normalized by the fractured interface area.

$$
\begin{aligned}
W & =\int_{0}^{u_{0}} P \mathrm{~d} u, \\
G_{F} & =\frac{W}{A}=\frac{W}{t(h-a)},
\end{aligned}
$$

where $W$ is the fracture work, which is the area under the load-displacement curve.

At intermediate and high temperatures, asphalt concretes exhibit viscoelastic-plastic behaviors in this scenario. Linear elastic fracture mechanics is no longer applicable due to the fact that the plastic zone ahead of the crack tip cannot be neglected. To evaluate the fracture resistance, the critical strain energy release rate, also called the critical value of J-integral [49], was employed in this study to evaluate the fracture resistance. $J$ integral is defined as the potential differences of energy between loaded samples possessing different notch length, and it expresses the amount of external energy in order to propagate the crack in the specimens. J integral calculation can be used in equation (5). It should be noted that, in linear elastic fracture mechanics, $J_{\mathrm{IC}}$ and $G_{\mathrm{F}}$ present the same meaning. Besides $J$ integral, fracture energy $\left(G_{F}\right)$ is also employed in evaluating the fracture performance at $25^{\circ} \mathrm{C}$.

$$
J_{\text {IC }}=\left(\frac{U_{1}}{t_{1}}-\frac{U_{2}}{t_{2}}\right) \times \frac{1}{a_{2}-a_{1}},
$$

where $U$ is the strain energy to the peak load (area underneath the load-deformation curve up to the peak load); $t$ is the specimen thickness; and a is the notch depth. The subscripts 1 and 2 refer to different notches 1 and 2, respectively.

\section{Test Results and Discussion}

4.1. Analysis of Fracture Parameters. Three typical loaddisplacement curves are plotted in Figure 5 considering the different temperatures, surface conditions, tack coat rates, and notch depths. The ascending part of the curve at $-10^{\circ} \mathrm{C}$ was more linear elastic than the curves at $25^{\circ} \mathrm{C}$. The descending curve at $-10^{\circ} \mathrm{C}$ is rather steeper and straighter than the curves at $25^{\circ} \mathrm{C}$. Specimens at $-10^{\circ} \mathrm{C}$ underwent complete fracture in a shorter time than at $25^{\circ} \mathrm{C}$. The differences in the curves are mainly ascribed to the fact that when the temperature increased from -10 to $25^{\circ} \mathrm{C}$, the tack 


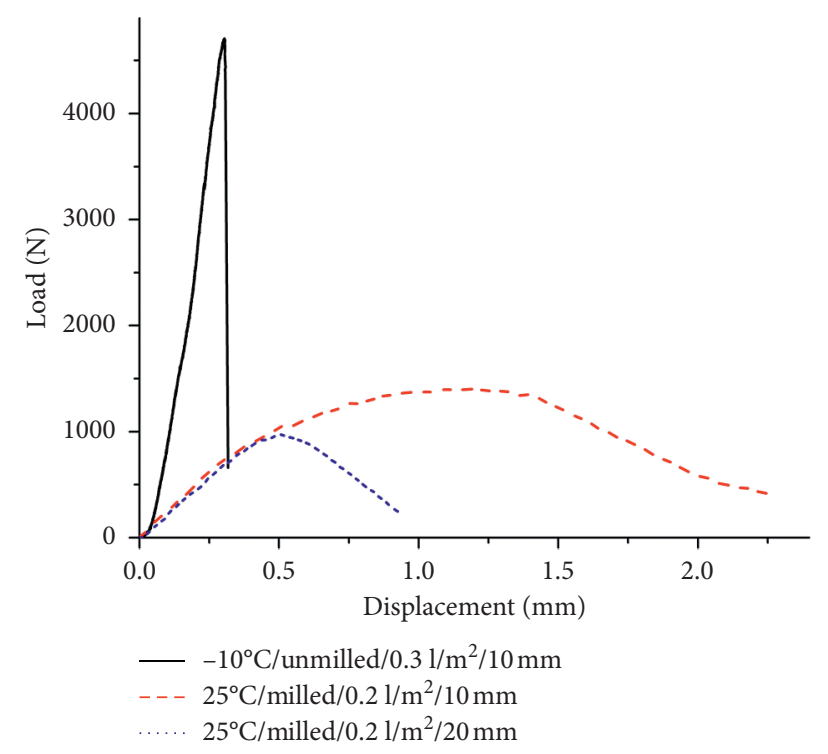

Figure 5: Load-displacement curves.

coat and the asphalt concrete changed from brittle materials to viscoplastic materials.

Figure 6 shows the fracture strengths of all the specimens. It can be observed that peak strengths decreased significantly when the temperature increased from $-10^{\circ} \mathrm{C}$ to $25^{\circ} \mathrm{C}$. Besides, when the notch depth increased from $10 \mathrm{~mm}$ to $20 \mathrm{~mm}$, strengths also significantly decreased for specimens with the same tack coat rate and the same surface condition. At $-10^{\circ} \mathrm{C}$, for specimens with unmilled surfaces, peak strengths gradually decreased when the tack coat rates increased in the interval $[0.1,0.4] \mathrm{L} / \mathrm{m}^{2}$, while, for specimens with milled surfaces, the optimum tack coat rate was $0.3 \mathrm{~L} /$ $\mathrm{m}^{2}$, at which the facture strength obtained the maximum value. The optimum tack coat rates at $25^{\circ} \mathrm{C}$ were 0.1 and $0.3 \mathrm{~L} / \mathrm{m}^{2}$ for specimens with milled and unmilled surfaces, respectively. A preliminary conclusion was that the optimum tack coat rate increased with the increase of roughness. This was mainly contributed by the fact that a rougher interface generally induced a larger interface area; a larger amount of tack coat would be needed to ensure an adequate bonding [34]. At $-10^{\circ} \mathrm{C}$, the maximum peak strength for specimens with milled surface was slightly larger than specimens with unmilled surface, and the increase amplitude was about $5.3 \%$, while, at $25^{\circ} \mathrm{C}$, when the surface changed from the unmilling state to milling state, the increase amplitudes were $-2.5 \%$ and $1.0 \%$ for 10 and $20 \mathrm{~mm}$ notch lengths, respectively. The results indicated that the interface roughness could not play a positive effect on the peak loads of the fracture tests, and a larger roughness may even weaken the peak load.

Tang et al. [23] conducted some direct shear tests and found a larger surface roughness contributed to a superior shear performance at all temperatures. The results derived from direct shear tests were slightly different with this study. This is because failure modes in direct shear tests and mode I fracture tests are different. In mode I fracture, the opening of cracks is mainly related to the cohesive strength rather than the internal friction along the cracks. In direct shear tests, the internal friction along the interface could be significantly affected by the interface roughness. The larger the roughness, the more obvious the internal friction. Considering the different effect of internal friction in different test methods, a unified relationship is suggested to be set up in the future.

Stress intensity factors $\left(K_{\mathrm{IC}}\right)$ were calculated only at $-10^{\circ} \mathrm{C}$ considering the linear elastic behaviors of the interface fracture. $K_{\mathrm{IC}}$ is just the function of the parameterpeak load, and other parameters in equation (4) were all constants. Therefore, specimens with unmilled and milled surfaces obtained the maximum $K_{\text {IC }}$ when the tack coat rates were 0.1 and $0.3 \mathrm{~L} / \mathrm{m}^{2}$, respectively. The stress intensity factors of specimens with milled surfaces were larger than specimens with unmilled surfaces (Figure 7). The milling surface was with a larger interface roughness. It was reported a larger texture depth may induce a better bonding performance [50]. Leng et al. [51] pointed out that milled PCC surfaces performed better than smooth and tined surfaces. A rougher interface may enhance the interlock effect between concrete layer and the asphalt overlay. Therefore, the fracture performance induced by a rougher interface may be larger.

Figure 8 shows the fracture energies of all specimens. At $-10^{\circ} \mathrm{C}$, the maximum energy release rate of specimens with milled surface was larger than that of the unmilled surface by $9.8 \%$, indicating milled interface enhanced the fracture resistance between asphalt and concrete layers at the low temperature. At $25^{\circ} \mathrm{C}$, a larger notch depth $(20 \mathrm{~mm})$ obviously lowered the fracture energy. When the specimens had the same notch length, the area under the load-displacement curve at $25^{\circ} \mathrm{C}$ was larger than that at $-10^{\circ} \mathrm{C}$, which can be observed from Figure 5 . Therefore, fracture energies at $25^{\circ} \mathrm{C}$ were larger than those at $-10^{\circ} \mathrm{C}$. The effect of temperature on fracture energies was the 


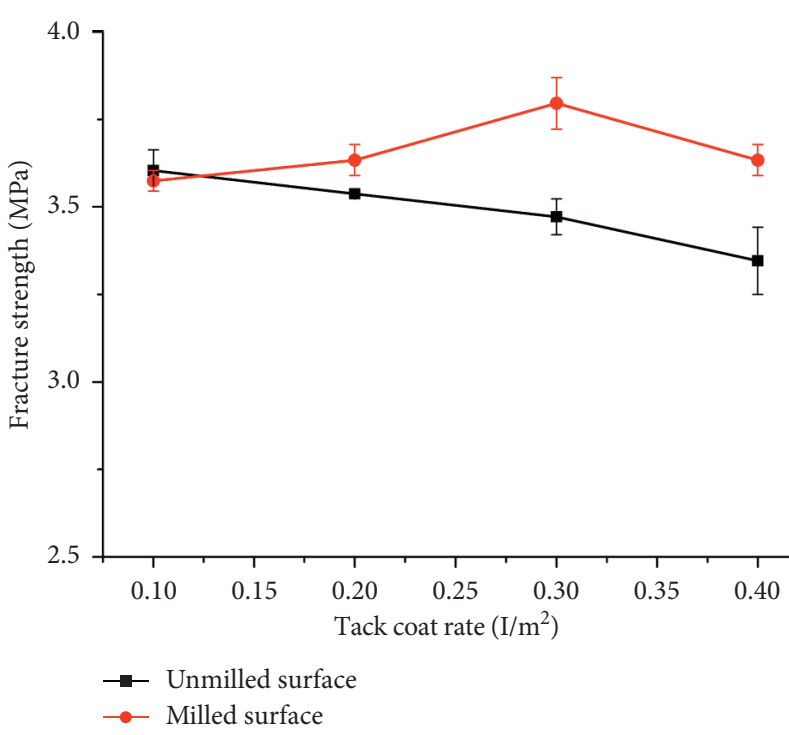

(a)

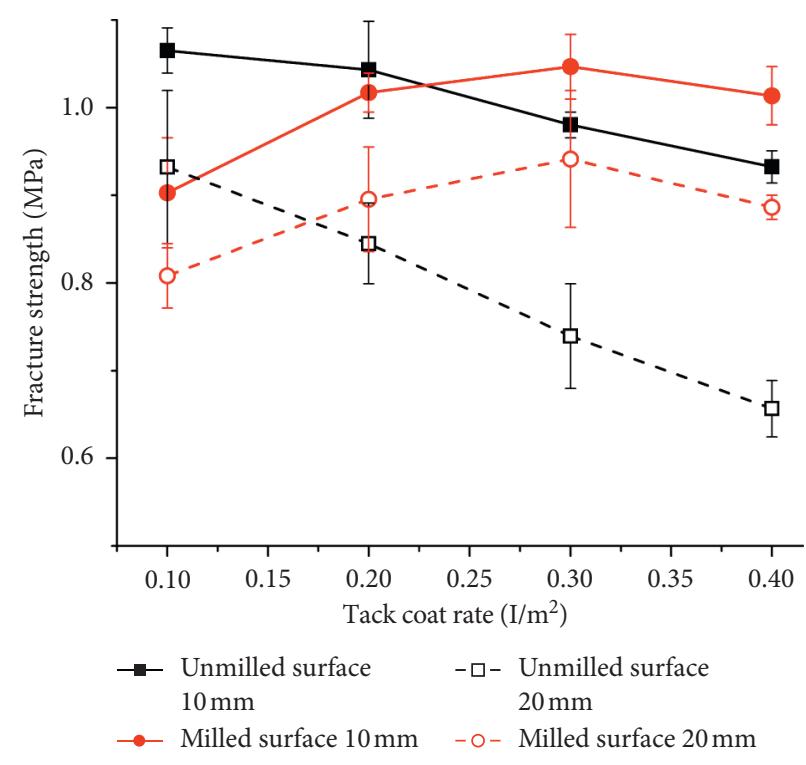

(b)

Figure 6: Fracture strength. (a) $-10^{\circ} \mathrm{C}$ and (b) $25^{\circ} \mathrm{C}$.

same as [52]. For specimens with $10 \mathrm{~mm}$ notch depth at $25^{\circ} \mathrm{C}$, the maximum energies for specimens with different interface conditions were nearly the same, which were obtained at tack coat rates 0.1 and $0.2 \mathrm{~L} / \mathrm{m}^{2}$. For specimens with $20 \mathrm{~mm}$ notch length, insignificant difference was also observed between the specimens with milled and unmilled interfaces. Hakimzadeh et al. [41] conducted mode I fracture tests between two asphalt layers. When the tack coat rate increased from 0.45 to $0.9 \mathrm{~L} / \mathrm{m}^{2}$ at $-12^{\circ} \mathrm{C}$, the fracture energy increased from 97 to $131 \mathrm{~J} / \mathrm{m}^{2}$. In this study, the fracture energy varied from 114 to $136 \mathrm{~J} / \mathrm{m}^{2}$ at $-10^{\circ} \mathrm{C}$ considering the different tack coat rates and interface conditions. Although the materials properties of this study are different from [41], the data range of this study is close to the published data.

At $25^{\circ} \mathrm{C}, J$ integrals were calculated using equation (5) and plotted for specimens with different surface conditions and different tack coat rates in Figure 9. It can be clearly observed that the optimum tack coats were 0.1 and $0.3 \mathrm{~L} / \mathrm{m}^{2}$. The maximum $J$ integral for specimens with milled surfaces was $1.527 \mathrm{~kJ} / \mathrm{m}^{2}$, which was reduced by $4.4 \%$ in contrast to the specimens with unmilled surfaces, indicating a larger interface roughness may weaken the fracture performance at intermediate temperatures.

4.2. Statistical Analysis. Three-way and two-way analysis of variance (ANOVA) were conducted to analyze the significance of factors on peak loads. In the three-way ANOVA analysis (Table 5), peak load was treated as the response variable, while surface condition, tack coat rate, and temperature were regarded as factors. Surface roughness and temperature were regarded as significant factors due to the fact that their probabilities were lower than 0.05 . However, the probability of tack coat rate was larger than 0.05 , indicating tack coat rate was not a significant factor at the $95 \%$

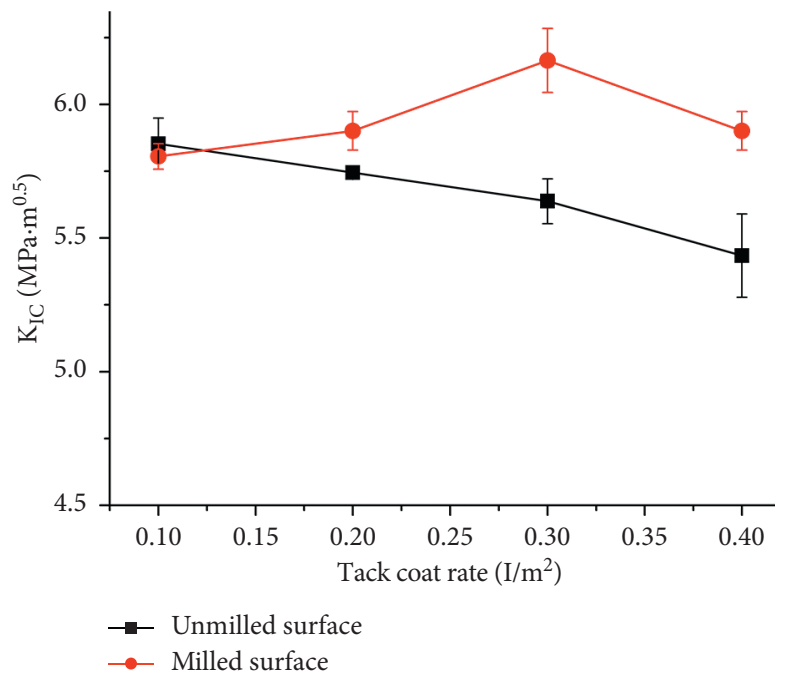

FIgURE 7: Stress intensity factors at $-10^{\circ} \mathrm{C}$.

confidence interval. Other factors (surface condition and temperature) and the interactions between them were all significant in influencing the peak loads.

Considering just two factors, two-way ANOVAs were conducted and the results are shown in Tables 6 and 7. In Table 6 , tack coat rate and temperature are influencing factors, and it can be observed that probabilities of tack coat rate were 0.0203 and 0.0277 for unmilled surface and milled surfaces, respectively. It suggests that, for a given surface, tack coat rate is significant in influencing the peak loads. When considering the effects of surface condition and tack coat rate (Table 7), the probabilities of surface roughness were 0.0028 and 0.7111 at $-10^{\circ} \mathrm{C}$ and $25^{\circ} \mathrm{C}$, respectively, indicating surface roughness is a significant factor at $-10^{\circ}$, while nonsignificant at $25^{\circ}$. The effect of surface roughness on the fracture behaviors is closely related to temperature. 


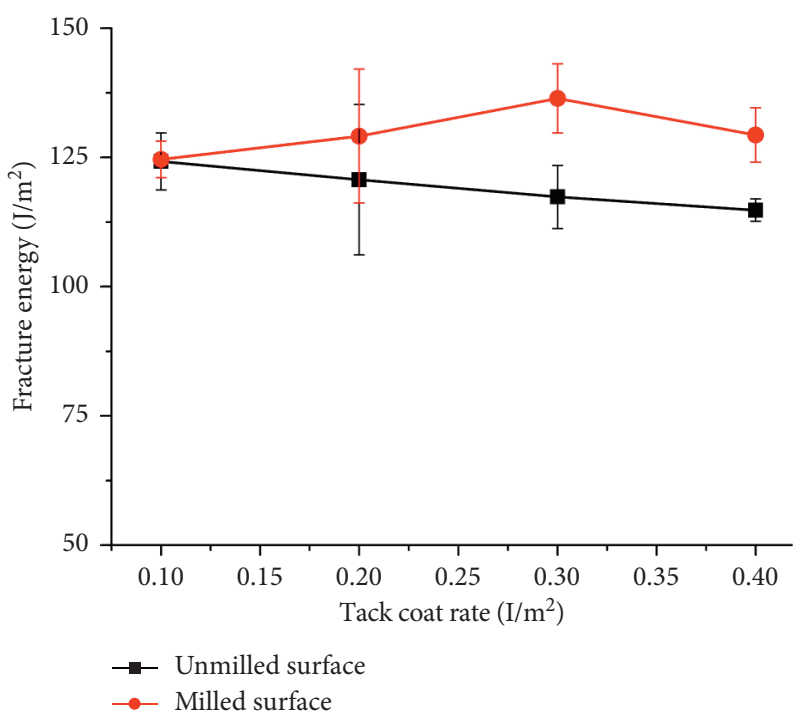

(a)

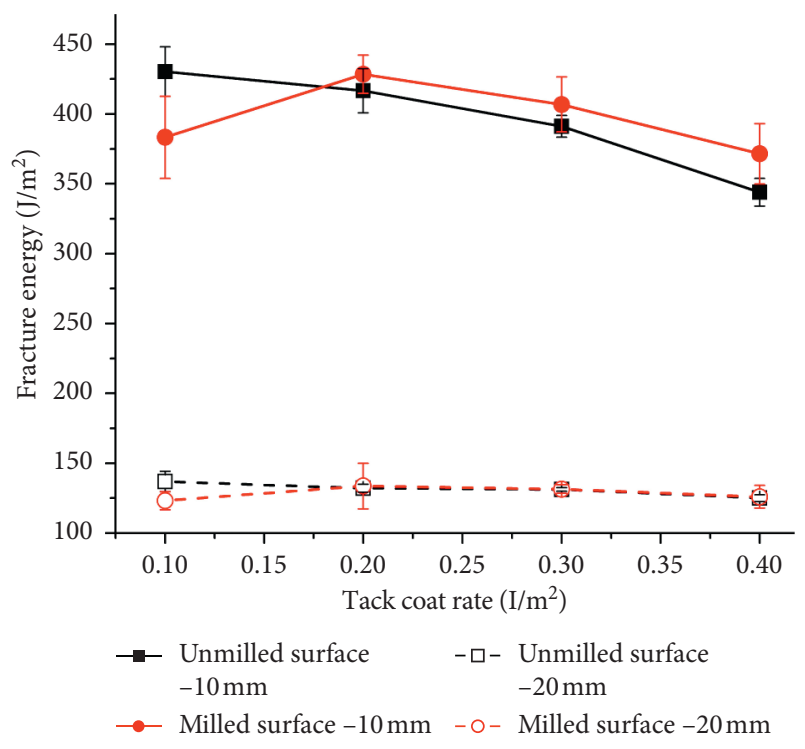

(b)

Figure 8: Fracture energy. (a) $-10^{\circ} \mathrm{C}$ and (b) $25^{\circ} \mathrm{C}$.

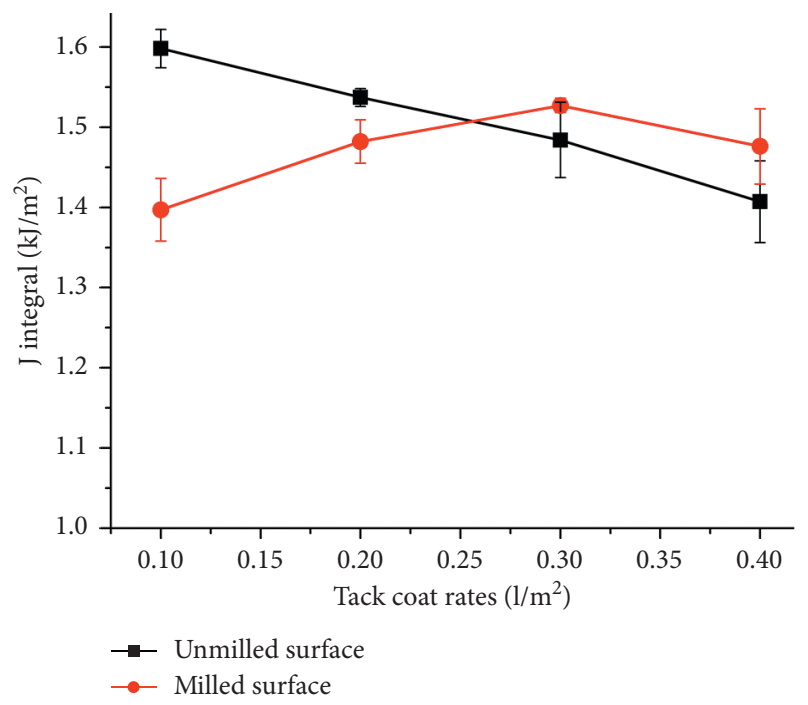

Figure 9: J integral.

TABLe 5: Three-way ANOVA results.

\begin{tabular}{|c|c|c|c|c|c|}
\hline Source & Sum sq. & $\mathrm{df}$ & Mean sq. & $\mathrm{F}$ & Prob $>F$ \\
\hline A & 0.0935 & 1 & 0.0935 & 11.06 & 0.0043 \\
\hline B & 0.0716 & 3 & 0.0239 & 2.82 & 0.072 \\
\hline $\mathrm{C}$ & 97.6154 & 1 & 97.6154 & 11547.85 & 0 \\
\hline $\mathrm{A} * \mathrm{~B}$ & 0.2102 & 3 & 0.0701 & 8.29 & 0.0015 \\
\hline $\mathrm{A} * \mathrm{C}$ & 0.1188 & 1 & 0.1188 & 14.06 & 0.0018 \\
\hline $\mathrm{B} * \mathrm{C}$ & 0.0247 & 3 & 0.0082 & 0.97 & 0.4297 \\
\hline $\mathrm{A} * \mathrm{~B} * \mathrm{C}$ & 0.0114 & 3 & 0.0038 & 0.45 & 0.7202 \\
\hline Error & 0.1352 & 16 & 0.0085 & & \\
\hline Total & 98.2809 & 31 & & & \\
\hline
\end{tabular}

Note. A: interface roughness; B: tack coat rate; C: temperature. 
TABle 6: Two-way ANOVA results of specimens with different surfaces.

\begin{tabular}{lcccccc}
\hline $\begin{array}{l}\text { Surface } \\
\text { condition }\end{array}$ & Source & Sum sq. & df & $\begin{array}{c}\text { Mean } \\
\text { sq. }\end{array}$ & F & Prob $>F$ \\
\hline \multirow{4}{*}{ Unmilled } & B & 0.1591 & 3 & 0.053 & 5.86 & $\mathbf{0 . 0 2 0 3}$ \\
surface & C & 45.4613 & 1 & 45.4613 & 5026.82 & 0 \\
& B C & 0.015 & 3 & 0.005 & 0.55 & 0.6611 \\
& Error & 0.0723 & 8 & 0.009 & & \\
& Total & 45.7077 & 15 & & & \\
\hline \multirow{4}{*}{ Milled } & B & 0.1288 & 3 & 0.0409 & 5.2 & $\mathbf{0 . 0 2 7 7}$ \\
surface & C & 52.2729 & 1 & 52.2729 & 6648.38 & 0 \\
& B C & 0.0212 & 3 & 0.0071 & 0.9 & 0.4838 \\
& Error & 0.0629 & 8 & 0.0079 & & \\
\hline & Total & 52.4797 & 15 & & & \\
\hline
\end{tabular}

Note. A: interface roughness; B: tack coat rate; C: temperature.

Table 7: Two-way ANOVA results of specimens at different temperatures.

\begin{tabular}{lcccccc}
\hline $\begin{array}{l}\text { Temperature } \\
\left({ }^{\circ} \mathrm{C}\right)\end{array}$ & Source & Sum sq. & df & $\begin{array}{c}\text { Mean } \\
\text { sq. }\end{array}$ & F & Prob $>F$ \\
\hline \multirow{4}{*}{-10} & $\mathrm{~A}$ & 0.2116 & 1 & 0.2116 & 17.97 & 0.0028 \\
& $\mathrm{~B}$ & 0.081 & 3 & 0.027 & 2.29 & $\mathbf{0 . 1 5 4 8}$ \\
& $\mathrm{A}^{*} \mathrm{~B}$ & 0.1526 & 3 & 0.05087 & 4.32 & 0.0435 \\
& Error & 0.0942 & 8 & 0.01178 & & \\
& Total & 0.5394 & 15 & & & \\
\hline \multirow{4}{*}{25} & $\mathrm{~A}$ & 0.00076 & 1 & 0.00076 & 0.15 & $\mathbf{0 . 7 1 1 1}$ \\
& $\mathrm{B}$ & 0.01527 & 3 & 0.00509 & 0.99 & $\mathbf{0 . 4 4 4 3}$ \\
& $\mathrm{A}^{*} \mathrm{~B}$ & 0.06907 & 3 & 0.02302 & 4.49 & 0.0398 \\
& Error & 0.04105 & 8 & 0.00513 & & \\
\hline & Total & 0.12614 & 15 & & & \\
\hline
\end{tabular}

Note. A: interface roughness; B: tack coat rate; C: temperature.

All the data presented in Tables 5-7 were just derived from the tests in this study. Different tack coat, different underlying layer type, and other temperatures, etc. may produce different results. Further investigations need to be done to reveal the influences of these factors.

\section{Conclusions}

This study focused on investigating the mode I fracture behaviors between asphalt and concrete layers considering the effects of temperature, tack coat, and surface roughness. Fracture strength, stress intensity factor, fracture energy, and energy release rate were obtained. Statistical analysis was conducted to demonstrate the significance of the influencing factors. The results of this research yield the following conclusions:

(1) Temperature significantly deteriorated the bonding between asphalt and concrete layers in decreasing the fracture strength.

(2) Optimum tack coat application rates increased with the increase of interface roughness. A larger interface roughness helps enhance the fracture performance at $-10^{\circ} \mathrm{C}$, which plays no significant effect at $25^{\circ} \mathrm{C}$.

(3) $\mathrm{J}$ integral at $25^{\circ} \mathrm{C}$ reveals that the lower the roughness, the larger the $J$ integral, indicating interface roughness may weaken the fracture performance at intermediate temperatures.

(4) ANOVA results show that surface condition is a significant factor at the low temperature $\left(-10^{\circ} \mathrm{C}\right)$, while nonsignificant at $25^{\circ} \mathrm{C}$. Tack coat rate was nonsignificant in the three-way ANOVA tests, while it becomes significant for just a given interface surface.

(5) The effect of interface roughness on fracture behaviors is different from the case of direct shear test, in which a larger roughness induced an obvious internal friction, leading to a superior shear strength. A unified relationship among the results generated by different test methods is encouraged to build in the future.

(6) The tack coat and asphalt concrete are loading rate and temperature dependent. The initial cracks may exist within concrete layer or asphalt layer. The fracture may also occur in the cement concrete or asphalt concrete adjacent to the interface if the strengths of cement concrete and/or asphalt concrete are low. Therefore, additional tests are needed to identify mixed mode fracture and specify the viscoelastic effect of asphalt materials on the fracture performance.

\section{Data Availability}

The experimental data used to support the findings of this study are included within the article.

\section{Conflicts of Interest}

The authors declare no conflicts of interest.

\section{Acknowledgments}

This study was supported by the projects funded by the National Natural Science Foundation of China (Grant no. 51378504) and Guizhou Provincial Department of Transportation (Grant no. 2013-122-001), which the authors acknowledge.

\section{References}

[1] G. Montestruque, R. Rodrigues, M. Nods, and A. Elsing, "Stop of reflective crack propagation with the use of PET geogrid as asphalt overlay reinforcement," in 5th International RILEM Conference on Cracking in Pavements-Mitigation, Risk Assesment and Prevention, C. Petit, Ed., pp. 231-238, Al-Qadi IL et Millien A, Chicago, IL, USA, 2004.

[2] B. A. Tayeh, B. H. Abu Bakar, M. A. Megat Johari, and Y. L. Voo, "Mechanical and permeability properties of the interface between normal concrete substrate and ultra high performance fiber concrete overlay," Construction and Building Materials, vol. 36, pp. 538-548, 2012.

[3] V. J. Bulusu, S. R. Kusam, and A. R. Muppireddy, "A critical review of the PCA and IRC methods of thin white topping pavement design," Transportation Research Procedia, vol. 48, pp. 3764-3769, 2020.

[4] J. Baek, Modeling Reflective Cracking Development in Hot-Mix Asphalt Overlays and Quantification of Control Techniques, 
University of Illinois at Urbana-Champaign, Chicago, IL, USA, 2010.

[5] J. M. Vandenbossche and M. Barman, "Bonded whitetopping overlay design considerations for prevention of reflection cracking, joint sealing, and the use of dowel bars," Transportation Research Record: Journal of the Transportation Research Board, vol. 2155, no. 1, pp. 3-11, 2010.

[6] M. Pasetto, E. Pasquini, G. Giacomello, and A. Baliello, "Innovative composite materials as reinforcing interlayer systems for asphalt pavements: an experimental study," Road Materials and Pavement Design, vol. 20, no. 2, pp. S617-S631, 2019.

[7] X. Lan, N.-A. Noda, K. Mithinaka, and Y. Zhang, "The effect of material combinations and relative crack size to the stress intensity factors at the crack tip of a bi-material bonded strip," Engineering Fracture Mechanics, vol. 78, no. 14, pp. 25722584, 2011.

[8] T. Hull, J. Colligon, and A. Hill, "Measurement of thin film adhesion," Vacuum, vol. 37, no. 3-4, pp. 327-330, 1987.

[9] C. Raab, A. O. Abd El Halim, and M. N. Partl, "Interlayer bond testing using a model material," Construction and Building Materials, vol. 26, no. 1, pp. 190-199, 2012.

[10] W. Song, X. Shu, B. Huang, and M. Woods, "Effects of asphalt mixture type on asphalt pavement interlayer shear properties," Journal of Transportation Engineering, Part B: Pavements, vol. 144, no. 2, Article ID 4018021, 2018.

[11] J. Wang, F. Xiao, Z. Chen, X. Li, and S. Amirkhanian, "Application of tack coat in pavement engineering," Construction and Building Materials, vol. 152, pp. 856-871, 2017.

[12] C. Raab and M. Partl, "Laboratory study on interlayer bonding using cationic tack coats," in Proceedings of 7 th International RILEM Symposium ATCBM09 on Advanced Testing and Characterization of Bituminous Materials, pp. 3-12, Rhodes, Greece, December 2016.

[13] L. N. Mohammad, M. Raqib, and B. Huang, "Influence of asphalt tack coat materials on interface shear strength," Transportation Research Record: Journal of the Transportation Research Board, vol. 1789, no. 1, pp. 56-65, 2002.

[14] A. Bae, L. N. Mohammad, M. A. Elseifi, J. Button, and N. Patel, "Effects of temperature on interface shear strength of emulsified tack coats and its relationship to rheological properties," Transportation Research Record: Journal of the Transportation Research Board, vol. 2180, no. 1, pp. 102-109, 2010.

[15] W. Zhang, "Effect of tack coat application on interlayer shear strength of asphalt pavement: a state-of-the-art review based on application in the United States," International Journal of Pavement Research and Technology, vol. 10, no. 5, pp. 434445, 2017.

[16] K. Rashid, M. Ahmad, T. Ueda et al., "Experimental investigation of the bond strength between new to old concrete using different adhesive layers," Construction and Building Materials, vol. 249, Article ID 118798, 2020.

[17] Y. He, X. Zhang, R. D. Hooton, and X. Zhang, "Effects of interface roughness and interface adhesion on new-to-old concrete bonding," Construction and Building Materials, vol. 151, pp. 582-590, 2017.

[18] A. Abu-Tair, S. Rigden, and E. Burley, "Testing the bond between repair materials and concrete substrate," Materials Journal, vol. 93, no. 6, pp. 553-558, 1996.

[19] G. A. Sholar, G. C. Page, J. A. Musselman, P. B. Upshaw, and H. L. Moseley, "Preliminary investigation of a test method to evaluate bond strength of bituminous tack coats (with discussion)," Journal of the Association of Asphalt Paving Technologists, vol. 73, pp. 771-806, 2004.

[20] R. Ktari, F. Fouchal, A. Millien, and C. Petit, "Surface roughness: a key parameter in pavement interface design," European Journal of Environmental Civil Engineering, vol. 21, no. 1, pp. 27-42, 2017.

[21] M. Diakhaté, A. Millien, C. Petit, A. Phelipot-Mardelé, and B. Pouteau, "Experimental investigation of tack coat fatigue performance: towards an improved lifetime assessment of pavement structure interfaces," Construction and Building Materials, vol. 25, no. 2, pp. 1123-1133, 2011.

[22] M. E. Mohamad, I. S. Ibrahim, R. Abdullah, A. B. Abd. Rahman, A. B. H. Kueh, and J. Usman, "Friction and cohesion coefficients of composite concrete-to-concrete bond," Cement and Concrete Composites, vol. 56, pp. 1-14, 2015.

[23] Z. Tang, F. Huang, and H. Peng, "Effect of 3D roughness characteristics on bonding behaviors between concrete substrate and asphalt overlay," Construction and Building Materials, vol. 270, Article ID 121386, 2021.

[24] R. Ktari, A. Millien, F. Fouchal, I.-O. Pop, and C. Petit, "Pavement interface damage behavior in tension monotonic loading," Construction and Building Materials, vol. 106, pp. 430-442, 2016.

[25] A. C. Raposeiras, J. Rojas-Mora, E. Piffaut, D. MovillaQuesada, and D. Castro-Fresno, "Development of an estimative model for the optimal tack coat dosage based on aggregate gradation of hot mix asphalt pavements," Construction and Building Materials, vol. 118, pp. 1-10, 2016.

[26] F. Santagata, M. Partl, G. Ferrotti, F. Canestrari, and A. Flisch, Layer Characteristics Affecting Interlayer Shear Resistance in Flexible Pavements, pp. 221-256, Technical Session of the Association-of-Asphalt-Paving-Technologists, Philadelphia, PA, USA, 2008.

[27] S. Li, X. Liu, and Z. Liu, "Interlaminar shear fatigue and damage characteristics of asphalt layer for asphalt overlay on rigid pavement," Construction and Building Materials, vol. 68, pp. 341-347, 2014.

[28] S. Fallah and A. Khodaii, "Developing a fatigue fracture model for asphalt overlay reinforced with geogrid," Materials and Structures, vol. 49, no. 5, pp. 1705-1720, 2016.

[29] K. Jayakesh and S. N. Suresha, "Experimental investigation of interface treatment technique on interface shear bond fatigue behavior of ultra-thin whitetopping," Construction and Building Materials, vol. 161, pp. 489-500, 2018.

[30] A. Mateos, J. Harvey, J. Paniagua, F. Paniagua, and A. Fan, "Role of concrete-asphalt interface in bonded concrete overlays of asphalt pavements," in Proceedings of the 8th RILEM international conference on mechanisms of cracking and debonding in pavements, pp. 489-494, Springer, Nantes, France, June 2016.

[31] A. C. Raposeiras, D. Castro-Fresno, A. Vega-Zamanillo, and J. Rodriguez-Hernandez, "Test methods and influential factors for analysis of bonding between bituminous pavement layers," Construction and Building Materials, vol. 43, pp. 372-381.

[32] W. Song, X. Shu, B. Huang, and M. Woods, "Influence of interface characteristics on the shear performance between open-graded friction course and underlying layer," Journal of Materials in Civil Engineering, vol. 29, no. 8, Article ID 4017077, 2017.

[33] S. A. Romanoschi and J. B. Metcalf, "Characterization of asphalt concrete layer interfaces," Transportation Research Record: Journal of the Transportation Research Board, vol. 1778, no. 1, pp. 132-139, 2001. 
[34] G. White, "State of the art: interface shear resistance of asphalt surface layers," International Journal of Pavement Engineering, vol. 18, no. 10, pp. 887-901, 2017.

[35] M. Mubaraki and H. Sallam, "Reliability study on fracture and fatigue behavior of pavement materials using SCB specimen," International Journal of Pavement Engineering, vol. 21, no. 13, pp. 1-13, 2018.

[36] J. Jiang, F. Ni, Q. Dong, F. Wu, and Y. Dai, "Research on the fatigue equation of asphalt mixtures based on actual stress ratio using semi-circular bending test," Construction and Building Materials, vol. 158, pp. 996-1002, 2018.

[37] B. Huang, X. Shu, and G. Zuo, "Using notched semi circular bending fatigue test to characterize fracture resistance of asphalt mixtures," Engineering Fracture Mechanics, vol. 109, pp. 78-88, 2013.

[38] W. Song, B. Huang, and X. Shu, "Influence of warm-mix asphalt technology and rejuvenator on performance of asphalt mixtures containing 50\% reclaimed asphalt pavement," Journal of Cleaner Production, vol. 192, pp. 191-198, 2018.

[39] S. Khalilpour, E. BaniAsad, and M. Dehestani, "A review on concrete fracture energy and effective parameters," Cement and Concrete Research, vol. 120, pp. 294-321, 2019.

[40] M. M. Mirsayar, X. Shi, and D. G. Zollinger, "Evaluation of interfacial bond strength between Portland cement concrete and asphalt concrete layers using bi-material SCB test specimen," Engineering Solid Mechanics, vol. 5, no. 4, pp. 293-306, 2017.

[41] S. Hakimzadeh, N. A. Kebede, W. G. Buttlar, S. Ahmed, and M. Exline, "Development of fracture-energy based interface bond test for asphalt concrete," Road Materials and Pavement Design, vol. 13, no. 1, pp. 76-87, 2012.

[42] F. Mu, J. M. Vandenbossche, and D. J. Janssen, "Quantifying the mode I energy release rate for interface fracture of Portland cement concrete bonded to asphalt," American Concrete Institute Spring Convention, 2013.

[43] S. H. Alsayed, "Influence of superplasticizer, plasticizer, and silica fume on the drying shrinkage of high-strength concrete subjected to hot-dry field conditions," Cement and Concrete Research, vol. 28, no. 10, pp. 1405-1415, 1998.

[44] W. Song, J. Yi, H. Wu, X. He, Q. Song, and J. Yin, "Effect of carbon fiber on mechanical properties and dimensional stability of concrete incorporated with granulated-blast furnace slag," Journal of Cleaner Production, vol. 238, Article ID 117819, 2019.

[45] M. Pająk and T. Ponikiewskib, "Flexural behavior of selfcompacting concrete reinforced with different types of steel fibers," Construction and Building Materials, vol. 47, pp. 397-408, 2013.

[46] A. T. Zehnder, "Stress intensity factors," in Encyclopedia of Tribology, Q. J. Wang and Y.-W. Chung, Eds., pp. 3335-3340, Springer US, Boston, MA, USA, 2013.

[47] H. Tada, P. Paris, and G. Irwin, The Analysis of Cracks Handbook, ASME Press, New York, NY, USA, 2000.

[48] P.-E. Petersson, Crack Growth and Development of Fracture Zones in Plain Concrete and Similar Materials, Lund University, Lund, Sweden, 1981.

[49] M. A. Mull, K. Stuart, and A. Yehia, "Fracture resistance characterization of chemically modified crumb rubber asphalt pavement," Journal of Materials Science, vol. 37, no. 3, pp. 557-566, 2002.

[50] W. Song, X. Shu, B. Huang, and M. Woods, "Factors affecting shear strength between open-graded friction course and underlying layer," Construction and Building Materials, vol. 101, pp. 527-535, 2015.
[51] Z. Leng, H. Ozer, I. L. Al-Qadi, and S. H. Carpenter, "Interface bonding between hot-mix asphalt and various portland cement concrete surfaces," Transportation Research Record: Journal of the Transportation Research Board, vol. 2057, no. 1, pp. 46-53, 2008.

[52] E. Tschegg, J. Macht, M. Jamek, and J. Steigenberger, "Mechanical and fracture-mechanical properties of asphalt-concrete interfaces," ACI Materials Journal, vol. 104, no. 5, pp. 474-480, 2007. 